\title{
SOLVING THE FELDSTEIN-HORIOKA PUZZLE WITH FINANCIAL FRICTIONS
}

\author{
BY YAN BAI AND JING ZHANG ${ }^{1}$
}

\begin{abstract}
Unlike the prediction of a frictionless open economy model, long-term average savings and investment rates are highly correlated across countries-a puzzle first identified by Feldstein and Horioka (1980). We quantitatively investigate the impact of two types of financial frictions on this correlation. One is limited enforcement, where contracts are enforced by the threat of default penalties. The other is limited spanning, where the only asset available is noncontingent bonds. We find that the calibrated model with both frictions produces a savings-investment correlation and a volume of capital flows close to the data. To solve the puzzle, the limited enforcement friction needs low default penalties under which capital flows are much lower than those in the data, and the limited spanning friction needs to exogenously restrict capital flows to the observed level. When combined, the two frictions interact to endogenously restrict capital flows and thereby solve the Feldstein-Horioka puzzle.
\end{abstract}

KEYWORDS: Feldstein-Horioka, savings, investment, financial frictions, limited enforcement, international capital flows.

\section{INTRODUCTION}

THE FELDSTEIN-HORIOKA (henceforth FH) puzzle is one of the most robust empirical regularities in international finance. Feldstein and Horioka (1980) found that a cross-country regression of average domestic investment rates on average domestic savings rates results in a large, positive regression coefficient. Their finding is tightly linked to the empirical observation that net capital flows across countries are small. Feldstein and Horioka conjectured that the FH coefficient should be zero in a frictionless world economy and concluded that there must be sizeable financial frictions in international capital markets.

Our objective is to quantitatively assess the implications of different financial frictions on the FH coefficient and the volume of capital flows across countries. To achieve this, we build a model with a continuum of small open economies. Each economy is a one-sector production economy that experiences idiosyncratic shocks to its total factor productivity (TFP). We analyze two financial frictions that are commonly studied in the literature. One is limited enforcement, where contracts are enforced by the threat of default penalties: perma-

\footnotetext{
${ }^{1}$ We are grateful for valuable comments and continuous encouragement from Patrick Kehoe, Timothy Kehoe, Linda Tesar, Richard Rogerson, Berthold Herrendorf, and Chris House. We thank four anonymous referees and a co-editor for many useful suggestions. For helpful comments, we also thank Cristina Arellano, David Backus, Rui Castro, V. V. Chari, Narayana Kocherlakota, Ellen McGrattan, Fabrizio Perri, Vivian Yue, and seminar and conference participants at Arizona State University, the Cleveland Fed, Florida State University, the Midwest Macroeconomic meeting 2005, the Minneapolis Fed, the NBER IFM November 2005, UBC, UIUC, the University of Iowa, the University of Michigan, the University of Minnesota, the University of Montreal, and the University of Texas. All remaining errors are our own.
} 
nent exclusion from financial markets and a loss in output. The other is limited spanning, which restricts the set of available assets to noncontingent bonds. ${ }^{2}$ We find that the interaction of these two frictions generates an FH coefficient and a volume of capital flows close to the data.

To understand the role of each friction, we first examine the frictionless model, where a full set of contingent contracts is traded and contracts are fully enforceable. This model generates substantial capital flows across countries; the average current-account-to-GDP ratio reaches an average of $62 \%$, much higher than the $7 \%$ observed in the data. The reason is that countries have a large incentive to borrow and lend so as to smooth consumption and allocate capital stocks efficiently, given the volatility of calibrated TFP shocks. The large volume of capital flows breaks the link between savings and investment, and leads to an FH coefficient close to zero.

We then turn to the enforcement model, in which countries trade a full set of assets but only have a limited capacity to enforce repayment. In this environment, state-contingent debt limits arise endogenously to ensure that countries never default on state-contingent liabilities. Given the volatile shock process and the benefit of trading contingent claims, the default penalties of permanent exclusion and output losses make continuation in international financial markets highly attractive. Countries therefore have little incentive to default. Consequently, the model implies large capital flows and a close-to-zero FH coefficient. To match the observed FH coefficient, we find that the default penalties have to be close to zero, that is, almost no exclusion from the markets and no loss in output. With this low default penalty, default incentives are high, and the volume of capital flows is much lower than that in the data. We conclude that limited enforcement alone cannot jointly reproduce the FH coefficient and the capital flows in the data.

We next consider the bond model, in which the spanning of assets is limited to a noncontingent bond. We follow the literature in imposing the natural debt limits to ensure that countries are able to repay without incurring negative consumption. ${ }^{3}$ The natural debt limits are quite loose and rarely bind in equilibrium. As a result, this model generates large capital flows and a counterfactually small FH coefficient. Clearly, as one tightens the debt limits exogenously, the implied FH coefficient increases. In particular, the bond model generates the observed FH coefficient when we set the exogenous debt limits tight enough to produce capital flows close to the data.

Our work shows that limited spanning and limited enforcement combine to endogenously reduce the volume of capital flows to a level consistent with the data. When countries trade noncontingent bonds with an option to default, endogenous debt limits are highly restrictive for two reasons. First, these

\footnotetext{
${ }^{2}$ Limited enforcement has been studied by Kehoe and Levine (1993), Kocherlakota (1996), and Kehoe and Perri (2002), among others. Limited spanning has been studied by Mendoza (1991), Aiyagari (1994), and Baxter and Crucini (1995), among others.

${ }^{3}$ See Aiyagari (1994) and Zhang (1997).
} 
debt limits have to ensure that countries prefer to repay, even under the worst realization of the TFP shock. Second, the benefits of staying in the markets are considerably lower when the only available asset is a noncontingent bond. Countries thus have a greater incentive to default, implying that the debt limits are tighter. These tight debt limits lead to a volume of capital flows of $10 \%$ and an FH coefficient close to that found in the data. They also help produce a degree of international risk sharing, cross-country dispersions of savings and investment rates, and time-series volatilities of output, consumption, and net exports close to those found in the data.

It is well known that savings and investment data are highly correlated not only across countries, but also in the time series of a given country. ${ }^{4}$ Our work demonstrates that the cross-country correlation, not the time-series correlation, helps evaluate the significance of financial frictions. All of our models produce a positive time-series correlation independently of financial frictions because both savings and investment respond positively to persistent TFP shocks. This is consistent with the findings of Baxter and Crucini (1993) and Mendoza (1991). The cross-country correlation, however, does depend on financial frictions, which affect the ability of countries to borrow and the degree of divergence between the average savings and investment rates.

Our work builds on Castro (2005), who demonstrated that the bond model can explain the FH finding when exogenous debt limits are calibrated to match the observed capital flows. While this is an important contribution, Castro's analysis leaves the source of the debt limits unexplained. The contribution of our work is to identify one potential source for these required debt limits: the interaction of the limited spanning and limited enforcement frictions. Understanding the source of debt limits is important if one is interested in how savings, investment, and capital flows respond to changes in default penalties or contracting technologies.

Our work is closely related to Kehoe and Perri (2002). They found that limited enforcement severely restricts capital flows when default penalties consist of permanent exclusion from financial markets but no drop in output. In contrast, we find under the same default penalties that limited enforcement barely restricts capital flows. The difference comes from two sources. First, our shock process is more volatile than theirs. We calibrate to TFPs of both developed and developing countries, while they calibrate to those of developed countries only. Second, our multicountry model offers more insurance opportunities than their two-country model. Thus, in our model, there is both a greater need and a greater opportunity to insure, which leads to larger capital flows.

Our two-friction model builds on Zhang (1997), who studied endogenous debt limits in a pure exchange economy. In his setup, the debt limits depend only on exogenous endowment shocks and are independent of agents' choices.

\footnotetext{
${ }^{4}$ Tesar (1991) documented that savings and investment are highly correlated over time.
} 
In contrast, in our production economy, the debt limits depend on both exogenous shocks and endogenous capital stocks. Thus, countries affect the debt limits they face through their choices of capital stocks. ${ }^{5}$

Relative to the vast empirical literature, there are few theoretical studies on the FH finding. Westphal (1983) argued that the FH finding is due to official capital controls. This finding, however, has persisted even after the widespread dismantling of capital controls. Obstfeld (1986) argued that population growth might generate a savings-investment comovement in a life-cycle model. Summers (1988), however, showed that the FH finding persists even after controlling for population growth. Barro, Mankiw, and Sala-I-Martin (1995) showed in a deterministic model that the savings and investment rates are perfectly correlated under full capital mobility after countries reach steady states. We instead show in a stochastic model that these two rates are uncorrelated under full capital mobility.

The rest of the paper is organized as follows. Section 2 confirms the FH finding with updated data. Section 3 shows that the FH puzzle can be resolved by combining limited spanning and limited enforcement. In Section 4, we study each friction in isolation. We conclude in Section 5. The Supplemental Material (Bai and Zhang (2010)) comprises two technical appendixes.

\section{THE PUZZLE CONFIRMED}

Feldstein and Horioka (1980) found a positive correlation between longterm savings and investment rates across countries. This finding is interpreted as a puzzle relative to a world with a frictionless financial market, which is an assumption behind most of the models in international economics. In this section, we reexamine the Feldstein-Horioka finding with updated data and show that the Feldstein-Horioka puzzle still exists today.

In their seminal paper, Feldstein and Horioka (1980) measured the long-run cross-country relationship between savings and investment rates by estimating

$$
(I / Y)_{i}=\gamma_{0}+\gamma_{1}(S / Y)_{i}+\varepsilon_{i},
$$

where $Y$ is gross domestic product (GDP), $S$ is gross domestic savings (GDP minus private and government consumption), $I$ is gross domestic investment, and $(S / Y)_{i}$ and $(I / Y)_{i}$ are period averages of savings rates and investment rates for each country $i$. All the variables are in nominal terms. Feldstein and Horioka took the long-period averages of these rates to handle the cyclical endogeneity of savings and investment rates. The constant term $\gamma_{0}$ captures the impact of the common shocks that affect all the countries on the world

\footnotetext{
${ }^{5}$ Abraham and Carceles-Poveda (2010) studied a similar model but with aggregate production. The endogenous borrowing constraints depend on shocks and aggregate capital stock, and thus are independent of agents' choices.
} 
average savings and investment rates. ${ }^{6}$ The coefficient $\gamma_{1}$ tells us whether highsaving countries are also high-investing countries on average.

Obviously, the regression coefficient $\gamma_{1}$ should be one in a world with closed economies because domestic investment must be fully financed by domestic savings. Feldstein and Horioka argued that $\gamma_{1}$ should be zero in a world without financial frictions. Based on a sample of 16 Organization for Economic Cooperation and Development (OECD) countries $^{7}$ over the 15 -year period from 1960 to 1974 , they found that $\gamma_{1}$ is 0.89 with a standard error of 0.07 . They interpreted this finding as evidence of a high degree of financial frictions.

The Feldstein-Horioka finding stimulated a large empirical literature that attempted to refute the puzzle by studying different data samples and periods, by adding other variables to the original ordinary least squares regression, or by using different estimation methods. Across empirical studies, however, the FH coefficient has remained large and significant, although it has tended to decline in recent years (see Coakley, Kulasi, and Smith (1998) for a detailed review).

We confirm the Feldstein-Horioka finding using a data set with 64 countries for the period 1960-2003. ${ }^{8}$ We find that the FH coefficient is 0.52 with a standard error of 0.06 . Although lower than the original estimate, it is still positive and significantly different from zero. These results are robust to different subgroups of countries and subperiods (see Table I). ${ }^{9}$ Thus, the positive long-run correlation between savings and investment rates remains a pervasive regularity in the data.

TABLE I

CROSS-COUNTRY REGRESSION COEFFICIENTS

\begin{tabular}{lccc}
\hline \hline & \multicolumn{3}{c}{ FH Coefficient (s.e.) ${ }^{\mathrm{a}}$} \\
\cline { 2 - 4 } Group of Countries & $1960-2003$ & $1960-1974$ & $1974-2003$ \\
\hline Full sample (64 countries) & $0.52(0.06)$ & $0.60(0.07)$ & $0.46(0.05)$ \\
Subsample (16 OECD countries) & $0.67(0.11)$ & $0.61^{\mathrm{b}}(0.11)$ & $0.56(0.13)$ \\
\hline
\end{tabular}

\footnotetext{
${ }^{\mathrm{a}}$ The term s.e. refers to the standard error.

${ }^{\mathrm{b}}$ The new data source produces an FH coefficient different from Feldstein and Horioka's original estimate for the same sample. See Appendix A.3 for details.
}

\footnotetext{
${ }^{6}$ For more discussion, see Frankel (1992).

${ }^{7}$ These countries are Australia, Austria, Belgium, Canada, Denmark, Finland, Germany, Greece, Ireland, Italy, Japan, the Netherlands, New Zealand, Sweden, the United Kingdom, and the United States.

${ }^{8}$ For a detailed description of data, see Appendix A.

${ }^{9}$ To compare with the Feldstein-Horioka result, we take two subperiods (1960-1974 and 19742003) and two subgroups of countries (16 OECD countries and the rest of the countries).
} 
TABLE II

CROSS-COUNTRY SAVINGS, INVESTMENT, AND CAPITAL FlowS ${ }^{\mathrm{a}}$

\begin{tabular}{|c|c|c|c|c|c|c|c|c|}
\hline \multicolumn{2}{|c|}{ Mean } & \multicolumn{2}{|c|}{$\begin{array}{l}\text { Standard } \\
\text { Deviation }\end{array}$} & \multicolumn{3}{|c|}{ Correlation } & \multicolumn{2}{|c|}{ Capital Flows } \\
\hline$S / Y$ & $I / Y$ & $S / Y$ & $I / Y$ & $(S / Y, I / Y)$ & $\left(S / Y, g_{y}\right)$ & $\left(I / Y, g_{y}\right)$ & $C A / Y(\mathrm{std})$ & $T A / Y(\mathrm{std})$ \\
\hline 0.21 & 0.22 & 0.07 & 0.04 & 0.77 & 0.31 & 0.47 & $0.07(0.04)$ & $0.49(0.29)$ \\
\hline
\end{tabular}

a $g_{y}$ denotes average growth of real GDP per worker, $C A / Y$ denotes the average absolute current-account-to-GDP ratio, and $T A / Y$ denotes the average absolute foreign-asset-position-to-GDP ratio. The term std refers to the standard deviation across countries.

To further understand the FH finding, we decompose the FH coefficient $\gamma_{1}$ as

$$
\gamma_{1}=\operatorname{cor}\left((S / Y)_{i},(I / Y)_{i}\right) \frac{\operatorname{std}\left((I / Y)_{i}\right)}{\operatorname{std}\left((S / Y)_{i}\right)},
$$

where cor denotes the correlation and std denotes the standard deviation. We report the correlation between the average savings and investment rates and their standard deviations across countries in Table II. The average savings rate has a larger standard deviation than the average investment rate: 0.07 versus 0.04 . These two rates have a correlation of 0.77 . In addition, we find that countries that grow faster not only invest more, but also save more on average. In particular, the correlation of the average growth rate of GDP per worker with the average investment rate is 0.47 and that with the average savings rate is 0.31 . The sample mean of the savings rates is close to that of the investment rates, both of which are around $20 \%$.

Another way to examine the Feldstein-Horioka finding is by looking at differences between domestic savings and investment rates. A frictionless international financial market should allow domestic investment rates of countries to diverge widely from their savings rates. In the data, however, differences between savings and investment rates have not been large for most of the countries. The average of the absolute current-account-to-GDP ratios, referred to as the capital flow ratio for simplicity, is $7 \%$ for the 64 countries over the full period, as shown in Table II. The average of the absolute foreign-asset-positionto-GDP ratios is $49 \%$. International financial markets over this period do not seem to have enabled countries to reap the long-run gains from intertemporal trade.

\section{A SOLUTION FROM TWO FINANCIAL FRICTIONS}

Feldstein and Horioka interpreted their finding as an indication of a high degree of financial frictions. An open question is what kinds of financial frictions can explain the finding quantitatively. To address this question, we study two 
types of financial frictions. One is limited spanning, where countries are limited to trading one noncontingent asset. The other is limited enforcement of contracts, where contracts are enforced by the threat of a reversion to costly financial autarky. We find that the model with both frictions (labeled as the bondenforcement model) can solve the Feldstein-Horioka puzzle quantitatively.

\subsection{The Model Environment}

Following Clarida (1990), we consider a continuum of small open economies to study a large number of countries in a tractable fashion. All economies produce a homogeneous good that can be either consumed or invested. Each economy consists of a production technology and a benevolent government that maximizes utility on behalf of a continuum of identical domestic consumers. Countries face idiosyncratic shocks in their production technologies. The world economy has no aggregate uncertainty.

The production function is the standard Cobb-Douglas $A K^{\alpha} L^{1-\alpha}$, where $A$ denotes total factor productivity (TFP), $K$ is capital, and $L$ is labor. TFP has two components: one is a deterministic growth component that increases at rate $g_{a}$, is common across countries, and is constant across periods; the other is a country-specific idiosyncratic shock $a$, which follows a Markov process with finite support and transition matrix $\Pi$. The history of the idiosyncratic shock is denoted by $a^{t}$ and the probability of $a^{t}$, as of period 0 , is denoted by $\pi\left(a^{t}\right)$. We normalize each country's allocations by its labor endowment and the common deterministic growth rate $\left(1+g_{a}\right)^{1 /(1-\alpha)}$. The production function can thus be simplified to $a k^{\alpha}$, where lowercase letters denote variables after normalization. Each country $s_{0}$ is indexed by its initial idiosyncratic TFP shock, capital stock, and asset holding: $\left(a_{0}, k_{0}, b_{0}\right)$.

International financial markets are characterized by two frictions. One is limited spanning: the menu of available assets is restricted to noncontingent bonds. The other is limited enforcement: countries have the option to default and the extent to which countries can be penalized is restricted to a reversion to costly financial autarky. When countries have an option to repudiate their obligations, there must be some penalty for debt default to give borrowers an incentive to repay. Following the sovereign debt literature, we assume that debt contracts are enforced by exclusion from international financial markets as in Eaton and Gersovitz (1981) and an associated drop in output as in Bulow and Rogoff (1989).

In such an environment, the government in each country $s_{0}$ chooses a sequence of feasible allocations of consumption, capital stocks, and noncontingent bonds, denoted by $x=\left\{c\left(a^{t}\right), k\left(a^{t}\right), b\left(a^{t}\right)\right\}$, to maximize a continuum of identical consumers' utility given by

$$
\sum_{t=0}^{\infty} \sum_{a^{t}} \beta^{t} \pi\left(a^{t}\right) u\left(c\left(a^{t}\right)\right),
$$


where $\beta$ denotes the discount factor and $u$ denotes utility which satisfies the usual Inada conditions. ${ }^{10}$ Any feasible allocation must satisfy the budget constraints, the enforcement constraints, the natural debt limits, and the nonnegativity constraints on consumption and capital. The budget constraints are given by

$$
c\left(a^{t}\right)+k\left(a^{t}\right)-(1-\delta) k\left(a^{t-1}\right)+b\left(a^{t}\right) \leq a_{t} k\left(a^{t-1}\right)^{\alpha}+R_{t} b\left(a^{t-1}\right),
$$

where $R_{t}$ is the risk-free interest rate and $\delta$ is the per-period depreciation rate of capital.

The enforcement constraints capture the limited enforcement friction and require that the continuation utility must be at least as high as autarky utility for each possible future shock, that is,

$$
U\left(a^{t+1}, x\right) \geq V^{\mathrm{AUT}}\left(a^{t+1}, k\left(a^{t}\right)\right) \text { for any } a^{t+1} .
$$

The continuation utility under allocation $x$ from $a^{t+1}$ onward is given by

$$
U\left(a^{t+1}, x\right)=\sum_{\tau=t+1}^{\infty} \sum_{a^{\tau}} \beta^{\tau-t-1} \pi\left(a^{\tau} \mid a^{t+1}\right) u\left(c\left(a^{\tau}\right)\right),
$$

where $\pi\left(a^{\tau} \mid a^{t+1}\right)$ denotes the conditional probability of $a^{\tau}$ given $a^{t+1}$. The autarky utility from $a^{t+1}$ onward is given by

$$
V^{\mathrm{AUT}}\left(a^{t+1}, k\left(a^{t}\right)\right)=\max _{\left\{c\left(a^{\tau}\right), k\left(a^{\tau}\right)\right\}} \sum_{\tau=t+1}^{\infty} \sum_{a^{\tau}} \beta^{\tau-t-1} \pi\left(a^{\tau} \mid a^{t+1}\right) u\left(c\left(a^{\tau}\right)\right),
$$

subject to nonnegativity constraints $\left(c\left(a^{\tau}\right), k\left(a^{\tau}\right) \geq 0\right)$ and budget constraints given by

$$
c\left(a^{\tau}\right)+k\left(a^{\tau}\right)-(1-\delta) k\left(a^{\tau-1}\right) \leq(1-\lambda) a_{\tau} k\left(a^{\tau-1}\right)^{\alpha}
$$

for any $\tau \geq t+1$, with $k\left(a^{t}\right)$ given. Here the penalty parameter $\lambda$ represents a drop in output associated with defaulting on debt, which has been extensively documented in the sovereign debt literature; see Tomz and Wright (2007) and Cohen (1992). Two possible channels lead to output drops after default. One is the disruption of international trade and the other is the disruption of domestic financial systems. Either disruption could lead to output drops if either trade or banking credit is essential for production. We follow the sovereign debt literature and model the output loss exogenously.

\footnotetext{
${ }^{10} \mathrm{We}$ drop the country index $s_{0}$ for simplicity of notation when doing so does not cause any confusion.
} 
In the spirit of Aiyagari (1994), we impose the natural debt limits to ensure that countries are able to repay even under the lowest shock without incurring negative consumption:

$$
b\left(a^{t}\right) \geq-D\left(k\left(a^{t}\right)\right),
$$

where $D\left(k\left(a^{t}\right)\right)=\left(\underline{a} k\left(a^{t}\right)^{\alpha}+(1-\delta) k\left(a^{t}\right)\right) /(R-1)$ and $\underline{a}$ is the lowest potential TFP shock. In the presence of the enforcement constraints, the natural debt limits never bind in equilibrium. We impose these limits to rule out the Ponzi scheme that does not violate the enforcement constraints.

\subsection{Equilibrium and the Solution Strategy}

An equilibrium in the bond-enforcement model is a sequence of prices $\left\{R_{t}\right\}$ and allocations $\left\{c\left(a^{t}\right), k\left(a^{t}\right), b\left(a^{t}\right)\right\}$ such that allocations solve each country's problem given prices and that the world resource conditions are satisfied every period:

$$
\begin{aligned}
& \sum_{s_{0}} \sum_{a^{t}} \pi\left(a^{t}\right)\left[c\left(a^{t}, s_{0}\right)+k\left(a^{t}, s_{0}\right)\right. \\
& \left.\quad-(1-\delta) k\left(a^{t-1}, s_{0}\right)-a_{t} k\left(a^{t-1}, s_{0}\right)^{\alpha}\right]=0 .
\end{aligned}
$$

Since our model has no aggregate uncertainty, interest rates are constant under an invariant distribution. Given the interest rate $R$, each country's problem, labeled original problem, is to maximize utility given by (3) subject to the budget constraints (4), the enforcement constraints (5), the natural debt limits (6), and the nonnegativity constraints on consumption and capital.

The optimal allocation in the original problem is different from a competitive equilibrium where consumers decide on borrowing, since the consumers fail to internalize the impact of their choices on nationwide debt limits. This point was made by Jeske (2006). To decentralize the optimal allocation, we can impose taxes or subsidies on foreign borrowing and lending of each consumer in a competitive setting, similarly to Kehoe and Perri (2002) and Wright (2006). ${ }^{11}$

To compute the equilibrium, we restate our original problem recursively as

$$
W(a, k, b)=\max _{c, k^{\prime}, b^{\prime}} u(c)+\beta \sum_{a^{\prime} \mid a} \pi\left(a^{\prime} \mid a\right) W\left(a^{\prime}, k^{\prime}, b^{\prime}\right)
$$

subject to

$$
c+k^{\prime}-(1-\delta) k+b^{\prime} \leq a k^{\alpha}+R b,
$$

\footnotetext{
${ }^{11}$ For details see Bai and Zhang (2010).
} 


$$
\begin{aligned}
& c, k^{\prime} \geq 0, \quad b^{\prime} \geq-D\left(k^{\prime}\right), \\
& W\left(a^{\prime}, k^{\prime}, b^{\prime}\right) \geq V^{\mathrm{AUT}}\left(a^{\prime}, k^{\prime}\right) \quad \forall a^{\prime} .
\end{aligned}
$$

This technical approach is similar to the approach used in Abreu, Pearce, and Stacchetti (1990), ${ }^{12}$ with one key difference in that our problem is dynamic rather than repeated. Capital and bond holdings are endogenous state variables that alter the set of feasible allocations in the following period. Thus, they not only affect the current utility, but also the future prospects in the continuation of the dynamic problem. Nonetheless, we show that the original problem can be restated in such a recursive formulation following Atkeson (1991). ${ }^{13}$

We solve the P-problem iteratively. In each iteration $n$, we compute the corresponding optimal welfare $W_{n}$ given $W_{n-1}$ as

$$
W_{n}(a, k, b)=\max _{c, k^{\prime}, b^{\prime}} u(c)+\beta \sum_{a^{\prime} \mid a} \pi\left(a^{\prime} \mid a\right) W_{n-1}\left(a^{\prime}, k^{\prime}, b^{\prime}\right),
$$

subject to the constraints (7), (8), and

$$
W_{n-1}\left(a^{\prime}, k^{\prime}, b^{\prime}\right) \geq V^{\mathrm{AUT}}\left(a^{\prime}, k^{\prime}\right) \text { for all } a^{\prime} .
$$

One feature of this algorithm is that the domain $S_{n}$ of $W_{n}$ needs to be updated in each iteration. This is because, for $W_{n}$ to be well defined, the set of feasible allocations that satisfy the constraints (7), (8), and (10) needs to be nonempty for each state $(a, k, b) \in S_{n}$. Clearly, this set of feasible allocations depends on the continuation welfare $W_{n-1}$. In particular, when $W_{n-1}$ decreases, some states $(a, k, b)$ cannot find any feasible allocations. Thus, a smaller domain can be supported.

We now describe the details of our iterative algorithm. We start with a value of $W_{0}$ that is sufficiently high and a sufficiently large set of states $S_{0}$. Specifically, we set $S_{0}$ to include all the states under which the set of allocations that satisfy the constraints (7) and (8) is nonempty. We set $W_{0}$ as the optimal welfare in the P-problem under the constraints (7) and (8) only. For each $n \geq 1$, we construct $S_{n}$ given $W_{n-1}$ to include all the states that permit a nonempty set of feasible allocations. The associated welfare function $W_{n}$ on $S_{n}$ is constructed according to (9). Both sequences of $\left\{S_{n}\right\}$ and $\left\{W_{n}\right\}$ are decreasing, and converge to the limits $S$ and $W$, respectively. The limit $W$ corresponds to the optimal welfare in the original problem.

\footnotetext{
${ }^{12}$ We thank an anonymous referee for directing us to this alternative solution strategy. Relative to our original one, this approach improves computation efficiency. For details on both approaches see Bai and Zhang (2010).

${ }^{13}$ The model in Atkeson (1991) had a complete set of assets and private information, while our model has incomplete markets and complete information. Despite these differences, the adaptation of his approach is straightforward.
} 
We compute the equilibrium of the bond-enforcement model as follows. We start with an initial guess of the interest rate $R$. We then follow the above iterative algorithm to compute the optimal welfare $W$ and the associated optimal decision rules. We next find the invariant distribution and calculate the excess demand in the bond markets under this interest rate $R$. We finally update the interest rate and repeat the above procedures until the bond markets clear.

\subsection{Calibration}

To quantitatively evaluate the FH coefficient in the bond-enforcement model, we calibrate the model parameters. Countries share all parameter values that describe tastes and technology, and differ only in their shock realizations. As is standard in the literature, we adopt the constant elasticity of substitution utility function $u(c)=\left(c^{1-\sigma}-1\right) /(1-\sigma)$, where the risk aversion parameter $\sigma$ is chosen to be 2 . The discount rate $\beta$ is calibrated to be 0.89 to match the U.S. average real capital return of $4 \%$ per annum. The technology parameters are set to match U.S. equivalents: the capital depreciation rate $\delta$ is set at $10 \%$ per annum, and the capital share $\alpha$ is set at 0.33 .

The benchmark default penalties are permanent exclusion from financial markets and a loss in output. We set the output drop parameter $\lambda$ at $1.4 \%$, following Tomz and Wright (2007). Given the importance of the default penalties, in the next section we conduct a wide range of the sensitivity analysis. In particular, we experiment with different values of the output drop parameter and allow for partial exclusion under which countries can regain access to international financial markets with some probability each period after default.

Calibration of the world TFP process requires a rich stochastic process to capture the key features of the TFP series for a large number of countries. Using the standard growth accounting method, we compute a TFP series for each country. ${ }^{14}$ We take out the common deterministic trend of $1.01 \%$ from the logged TFP series.

There are three key features of the 64 TFP series. First, there is a wide range of TFP levels across countries. For example, the average TFP difference between the United States and Senegal is more than 13 times the cross-country average of time-series standard deviations. Second, TFPs of poor countries are generally more volatile than those of rich countries, as shown in Figure 1(a). The mean of the coefficients of variation of the TFP series is 0.02 for OECD countries and is 0.04 for developing countries. Third, TFPs for some countries have different characteristics during different subperiods, as shown in Figure 1(b). For example, Peruvian TFP shows an abrupt change in 1980: its coefficient of variation and the mean are 0.02 and 3.8 before 1980, and 0.05 and 3.5 after 1980.

\footnotetext{
${ }^{14}$ For details, see Appendix B.
} 


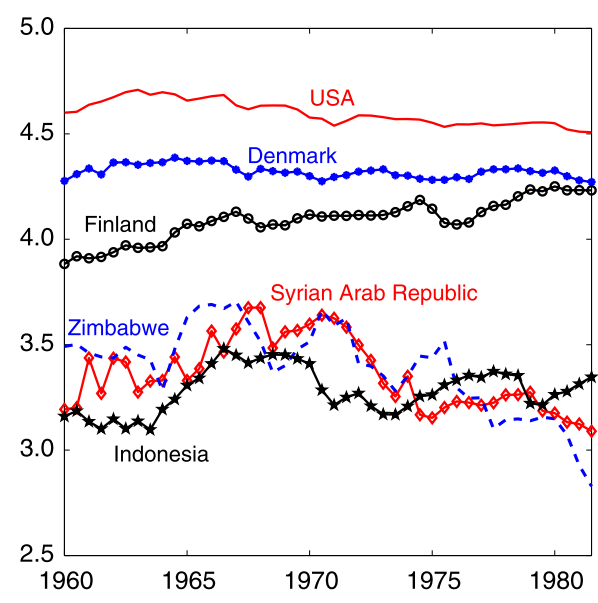

(a) Variation Across Countries

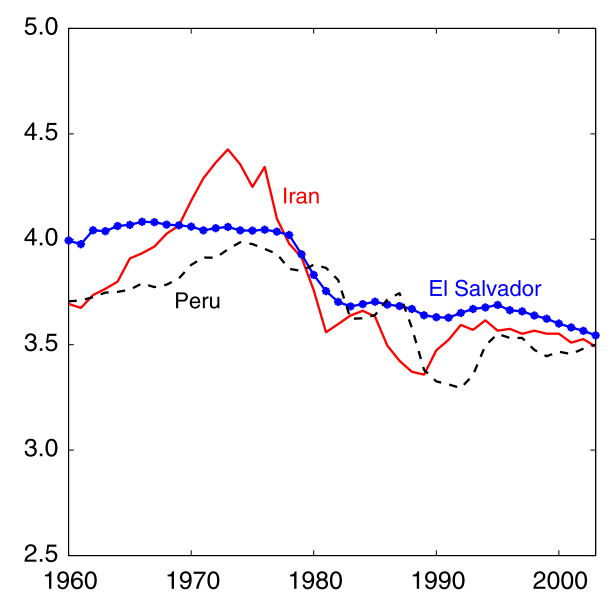

(b) Variation Across Time

FIGURE 1.-Key features of the TFP processes.

To generate the features of the TFP series in the data, we specify the world productivity process as a stochastic regime-switching process. We assume that the world has three regimes, each of which is captured by its mean, persistence, and standard deviation of innovations $\left\{\left(\mu_{j}, \rho_{j}, \nu_{j}\right)\right\}_{j=1,2,3} .{ }^{15}$ The TFP shock $a_{i t}$ of country $i$ at period $t$ in regime $j$ follows an autoregressive process

$$
a_{i t}=\mu_{j}\left(1-\rho_{j}\right)+\rho_{j} a_{i t-1}+\nu_{j} \varepsilon_{i t},
$$

where $\varepsilon_{i t}$ is independently and identically distributed, and drawn from a standard normal distribution. At period $t+1$, country $i$ has some probability of switching to another regime, governed by the transition matrix $P$.

Finally, we use maximum likelihood to estimate all the parameters. The estimation algorithm, described in Appendix B, is an extension of the expectation maximization (EM) principle of Hamilton (1989). Table III reports parameter estimates and standard errors. For convenience, the regimes will be referred to as the low, middle, and high regimes according to their conditional means. All three regimes are persistent with $\rho$ around 0.99 . The middle regime is more volatile than the other two regimes. Switching between regimes mimics abrupt changes of some countries' TFP processes in the data, such as those of Iran and Peru. The regime-switching process successfully replicates the key features of the cross-country TFP series.

\footnotetext{
${ }^{15}$ The three-regime specification greatly improves the goodness of fit over the two-regime specification, while introducing another regime barely improves the goodness of fit. For tractability, we choose the three-regime specification.
} 
TABLE III

Estimated PARAMETERS OF THE WORLD PRODUCTIVITY ProcesS ${ }^{\mathrm{a}}$

\begin{tabular}{lcccccc}
\hline & & & & \multicolumn{3}{c}{ Switching Probability $P$} \\
\cline { 5 - 7 } Regime & Mean $\mu$ & Innovation $\nu$ & Persistence $\rho$ & Low & Middle & High \\
\hline Low & $2.07(1.08)$ & $0.023(0.0001)$ & $0.995(0.003)$ & $0.92(0.11)$ & $0.04(0.15)$ & $0.04(0.08)$ \\
Middle & $3.46(0.37)$ & $0.070(0.0003)$ & $0.987(0.011)$ & $0.06(0.06)$ & $0.90(0.05)$ & $0.04(0.04)$ \\
High & $4.58(0.14)$ & $0.020(0.0000)$ & $0.981(0.003)$ & $0.04(0.14)$ & $0.03(0.19)$ & $0.93(0.10)$ \\
\hline
\end{tabular}

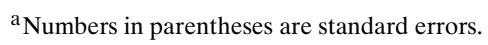

\subsection{Quantitative Results}

Now, with the calibrated parameters and the estimated world TFP process, we can compute the predictions of the bond-enforcement model by simulation. To be consistent with the empirical data, in each simulation we obtain 64 series of 44 periods from the invariant distribution. We then compute domestic savings as output minus consumption and domestic investment as changes in capital stocks plus capital depreciation. After calculating the average savings and investment rates, we run the same regression as in equation (1). We simulate the model 1,000 times. Table IV reports the results, along with comparisons to the data and the results from the other models. The bond-enforcement model generates an FH coefficient of 0.52 , significantly different from zero and similar to that in the data. Thus, this model solves the Feldstein-Horioka puzzle.

Our results come from the interaction of limited enforcement and limited spanning. These two frictions together generate endogenous debt limits on noncontingent bonds because lenders will not offer a loan that would be defaulted on in the next period. In particular, the endogenous debt limits $B$ depend on the current TFP shock $a$ and the next-period capital stock $k^{\prime}$ as

$$
B\left(a, k^{\prime}\right) \equiv \min _{a^{\prime} \mid \pi\left(a^{\prime} \mid a\right)>0}\left\{-\tilde{b}\left(a^{\prime}\right): W\left(a^{\prime}, k^{\prime}, \tilde{b}\left(a^{\prime}\right)\right)=V^{\mathrm{AUT}}\left(a^{\prime}, k^{\prime}\right)\right\} .
$$

For each $\left(a, k^{\prime}\right)$, the debt limit $B$ specifies the maximum amount of debt that can be supported without default under all future contingencies.

We examine features of the endogenous debt limits. Figure 2(a) plots the endogenous debt limit function $B$ over capital for the median shock in the middle-volatility regime. The debt limit is increasing in capital because poor countries have more incentive to default than rich countries. To interpret the scale of the debt limits, we also graph them in Figure 2(b) in terms of output. ${ }^{16}$

\footnotetext{
${ }^{16}$ The debt-limit-over-output ratio is not monotonically increasing in capital due to the concavity of the production function. The zigzag pattern in the figure is the result of the numerical approximation.
} 
TABLE IV

COMPARISON ACROSS MODELS ${ }^{\mathrm{a}}$

\begin{tabular}{lllcccc}
\hline \hline & \multicolumn{1}{c}{ Data } & $\begin{array}{c}\text { Two-Friction } \\
\text { Model }\end{array}$ & $\begin{array}{c}\text { Frictionless } \\
\text { Model }\end{array}$ & $\begin{array}{c}\text { Enforcement } \\
\text { Model }\end{array}$ & $\begin{array}{c}\text { Bond } \\
\text { Natural Limits }\end{array}$ & $\begin{array}{c}\text { Bond } \\
\text { ad hoc Limits }\end{array}$ \\
\hline FH coeff (s.e. $)$ & $0.52(0.06)$ & $0.52(0.05)$ & $-0.01(0.01)$ & $-0.01(0.02)$ & $0.05(0.02)$ & $0.52(0.05)$ \\
$C A / Y$ (std) & $0.07(0.04)$ & $0.10(0.09)$ & $0.62(0.33)$ & $0.56(0.27)$ & $0.38(0.13)$ & $0.11(0.09)$ \\
$T A / Y($ std $)$ & $0.49(0.29)$ & $0.40(0.21)$ & $6.12(5.15)$ & $4.10(1.76)$ & $5.60(3.44)$ & $0.39(0.23)$ \\
$\operatorname{std}(S / Y)$ & 0.06 & 0.06 & 0.41 & 0.28 & 0.34 & 0.06 \\
$\operatorname{std}(I / Y)$ & 0.04 & 0.04 & 0.05 & 0.04 & 0.04 & 0.04 \\
$\operatorname{cor}(S / Y, I / Y)$ & 0.77 & 0.77 & -0.09 & -0.10 & 0.39 & 0.77 \\
$\operatorname{cor}\left(S / Y, g_{y}\right)$ & 0.31 & 0.65 & 0.00 & 0.10 & 0.41 & 0.64 \\
$\operatorname{cor}\left(I / Y, g_{y}\right)$ & 0.47 & 0.66 & 0.89 & 0.83 & 0.88 & 0.68 \\
$\operatorname{mean}(S / Y)$ & 0.21 & 0.13 & -0.06 & -0.03 & 0.12 & 0.13 \\
$\operatorname{mean}(I / Y)$ & 0.22 & 0.14 & 0.21 & 0.21 & 0.21 & 0.15 \\
$\operatorname{RS} \operatorname{coeff}($ s.e. $)$ & $0.78(0.01)$ & $0.60(0.01)$ & $0.00(0.00)$ & $0.01(0.00)$ & $0.46(0.03)$ & $0.61(0.01)$ \\
$\operatorname{TS} \operatorname{cor}(\mathrm{std})$ & $0.49(0.42)$ & $0.73(0.04)$ & $0.52(0.10)$ & $0.38(0.14)$ & $0.61(0.02)$ & $0.74(0.04)$ \\
\hline
\end{tabular}

${ }^{a} C A / Y$ denotes the average absolute current-account-to-GDP ratio and $T A / Y$ denotes the average absolute foreign-asset-position-to-GDP ratio. The term std refers to the cross-country variation in the time-series average, cor denotes the correlation, and s.e. denotes the standard error. RS coeff reports coefficient $\beta_{1}$ in the panel regression: $\Delta \log c_{i t}-\Delta \log \bar{c}_{t}=\beta_{0}+\beta_{1}\left(\Delta \log y_{i t}-\Delta \log \bar{y}_{t}\right)+u_{i, t}$, where $\bar{c}_{t}$ and $\bar{y}_{t}$ denote the average consumption and output across countries of date $t$. TS cor denotes the average time-series correlations between detrended savings and investment using the Hodrick-Prescott (HP) filter. Bond ad hoc Limits denotes the bond model with the constraint (14), where $\kappa$ is set at $9.8 \%$ to match the observed FH coefficient.

These endogenous debt limits overall allow countries to borrow about $30 \%$ of their output on average. As a result, the model generates a capital flow ratio of $10 \%$ and a foreign-asset-to-output ratio of $40 \%$, which are close to their empirical counterparts of $7 \%$ and $49 \%$.

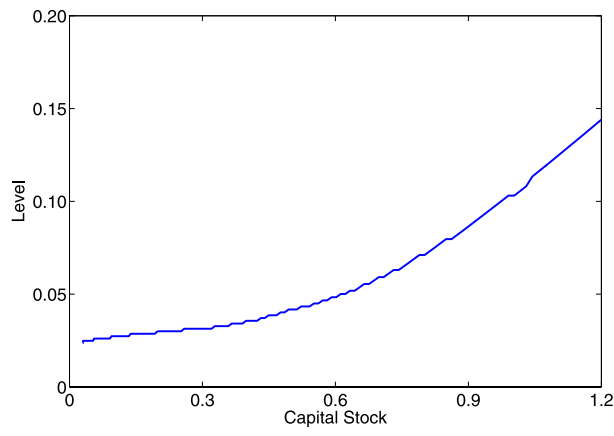

(a) Levels of Debt Limits

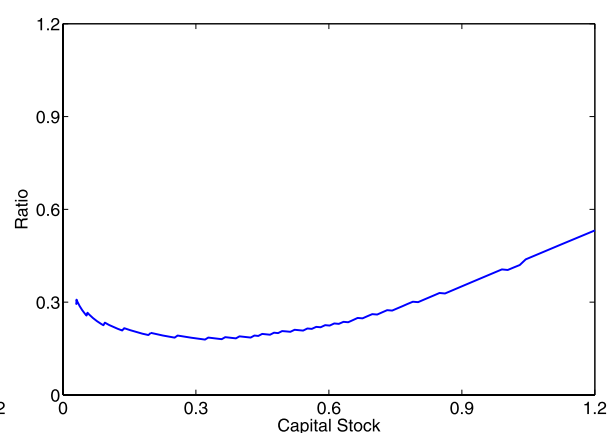

(b) Ratios of Debt Limits and Output

FIGURE 2.-Endogenous debt limits. 
The endogenous debt limits are key to understanding savings and investment behavior. Countries with low capital face tight debt limits and cannot borrow much to invest when they are experiencing good productivity shocks: they have to save more to invest more. Countries with high capital intend to lend abroad when they are experiencing bad shocks. Nonetheless, total lending must be equal to total borrowing in equilibrium. These countries have to invest more at home because the interest rate decreases to lower their lending incentive. Consequently, the average savings and investment rates are positively correlated across countries with a correlation of 0.77 , the same as that in the data. Also, the model produces small dispersions of savings and investment rates, similar to those found in the data; the standard deviations are 0.06 and 0.04 , respectively. Furthermore, the model generates positive correlations between the output growth and the savings and investment rates, although these correlations are higher than those in the data, as shown in Table IV.

\section{THE ROLE OF EACH FRICTION}

The bond-enforcement model deviates from the standard complete markets model in two ways: limited spanning of assets and limited enforcement of debt contracts. Could we have quantitatively solved the Feldstein-Horioka puzzle with just one of these? To address this question, we first examine the frictionless complete markets model, then examine the enforcement model where contingent contracts have limited enforceability, and finally examine the bond model where assets have limited spanning. Across these models, we maintain the benchmark parameter values with the exception that the discount factor is recalibrated in each model to match the interest rate of $4 \%$ per annum. ${ }^{17}$ By doing so, we highlight the impact of each financial friction, and more importantly their interaction, on capital flows and the FH coefficient.

\subsection{The Complete Markets Model}

Feldstein and Horioka conjecture that in a general equilibrium model of a world economy without financial frictions, the FH coefficient should be zero. Interestingly, Feldstein and Horioka made their conjecture long before there existed quantitative stochastic general equilibrium models that could be used to evaluate it. In this subsection, we verify the Feldstein-Horioka conjecture in a standard complete markets model.

Under frictionless financial markets, countries trade a complete set of Arrow securities. The government chooses allocations to maximize (3) subject to the

\footnotetext{
${ }^{17}$ The discount factor is calibrated to be 0.96 in the frictionless model, 0.955 in the benchmark enforcement model, and 0.94 in the bond model with the natural debt limits.
} 
budget constraints

$$
\begin{aligned}
& c\left(a^{t}\right)+k\left(a^{t}\right)+\sum_{a_{t+1} \mid a^{t}} q\left(a^{t}, a_{t+1}\right) b\left(a^{t}, a_{t+1}\right) \\
& \quad \leq a_{t} k\left(a^{t-1}\right)^{\alpha}+(1-\delta) k\left(a^{t-1}\right)+b\left(a^{t-1}, a_{t}\right)
\end{aligned}
$$

and the no-Ponzi constraints

$$
b\left(a^{t}, a_{t+1}\right) \geq-\bar{B}
$$

where $b\left(a^{t}, a_{t+1}\right)$ denotes the quantity of Arrow securities that deliver one unit of consumption if state $a_{t+1}$ is realized next period and $q\left(a^{t}, a_{t+1}\right)$ denotes the price of such Arrow securities. The borrowing limit $\bar{B}>0$ is set so large that the no-Ponzi constraints never bind in equilibrium. As reported in Table IV, the complete markets model generates an FH coefficient of $-0.01 .^{18}$ Thus, the frictionless model produces an FH coefficient close to zero, as Feldstein and Horioka conjectured.

To understand this result, we first look at investment and savings decisions. Under a persistent shock process, investment depends on changes of TFP shocks: a country with a higher average TFP growth rate invests more on average. Savings depends not on changes, but on levels of shocks: a country with a higher average TFP level saves more on average. As a result, the average growth of output is positively correlated with the average investment rate, but uncorrelated with the average savings rate, as reported in Table IV.

We then examine the two terms of the FH coefficient in equation (2): the correlation between the average savings and investment rates and their relative dispersion. The change and the level of our persistent and mean-reversion process are slightly negatively correlated, which implies a small, negative correlation between the average savings and investment rates of -0.09. Additionally, the relative dispersion of investment and savings is small because the change has a smaller dispersion than the level under the persistent shock process. Consequently, the frictionless model produces an FH coefficient close to zero. Additionally, the savings dispersion in the frictionless model is much larger than that in the two-friction model: 0.41 versus 0.06 , which implies that the two frictions have substantial impacts on limiting capital flows across countries.

This analysis shows that the size of the FH coefficient depends on the persistence of the TFP process. As the persistence decreases, the correlation between changes and levels of shocks becomes more negative, and the dispersion

\footnotetext{
${ }^{18}$ If savings is defined as national savings instead of domestic savings, the FH coefficient will be zero. The intuition is simple. National income and consumption of each country are constant over time due to fully diversified portfolios, which leads to constant national savings rates over time. Investment, however, varies with TFP shocks over time. Thus, average national savings rates and average investment rates are uncorrelated across countries.
} 
of changes relative to levels rises. Thus, the correlation between the average investment and savings rates becomes more negative, and the relative dispersion of the two rates rises with lower persistence. As a result, the $\mathrm{FH}$ coefficient becomes more negative. To illustrate this point, we vary the persistence parameter of an $\mathrm{AR}(1)$ process, where the innovation standard deviation is set at $4.2 \%$ to match the unconditional standard deviation of the TFP data. When persistence falls from 0.999 to 0.5 , the $\mathrm{FH}$ coefficient falls from -0.001 to -0.12 , but the FH puzzle remains.

The frictionless model generates a large capital flow ratio, 62\%, which is about 9 times that in the data. The average foreign-asset-position-to-GDP ratio is also large, 6.12, which is about 12 times that in the data. Furthermore, the pattern of capital flows deserves some attention. Rich, fast-growing countries on average both invest and save a lot, while poor, stagnant countries on average both invest and save little. Even under complete markets, these two types of countries have relatively low capital flows. Rich, stagnant countries on average save a lot but invest little, and poor, miracle countries on average save little but invest heavily. Thus, capital flows generally move from rich, stagnant to poor, miracle countries. This prediction is not observed in the data, as pointed out by Lucas (1990).

\subsection{The Enforcement Model}

We now examine the enforcement model. It allows a complete set of assets to be traded, but international financial contracts have limited enforceability. Formally, each country chooses an allocation $x=\left\{c\left(a^{t}\right), k\left(a^{t}\right), b\left(a^{t}, a_{t+1}\right)\right\}$ to maximize its welfare given by (3), subject to the budget constraints (12), the no-Ponzi constraints (13), and the enforcement constraints (5). ${ }^{19}$ As shown in Table IV, the enforcement model produces an FH coefficient of -0.01 and a capital flow ratio of 0.56 , which are close to the predictions of the frictionless model.

In this model, limited enforceability of contracts generates endogenous borrowing limits, which ensure that countries prefer to repay their contingent claims next period. Figure 3 plots these limits on contingent claims on the median shock of each regime. Borrowing limits are larger for countries with larger capital stocks or higher TFP shocks because they have less incentive to default. Moreover, these state-contingent debt limits are very loose when compared with the noncontingent debt limits in the two-friction model. On average, countries can borrow three times their income. This is because continued participation in financial markets is so attractive that countries have little incentive to default under the rich asset structure and the volatile shock process.

\footnotetext{
${ }^{19}$ Solving the enforcement model is computationally intensive. In addition to transforming the enforcement constraints recursively, we also need to deal with the curse of dimensionality that arises under state-contingent assets. We adapt the approach proposed by Atkeson and Lucas (1992) to compute this model. For details, see Zhang (2005).
} 


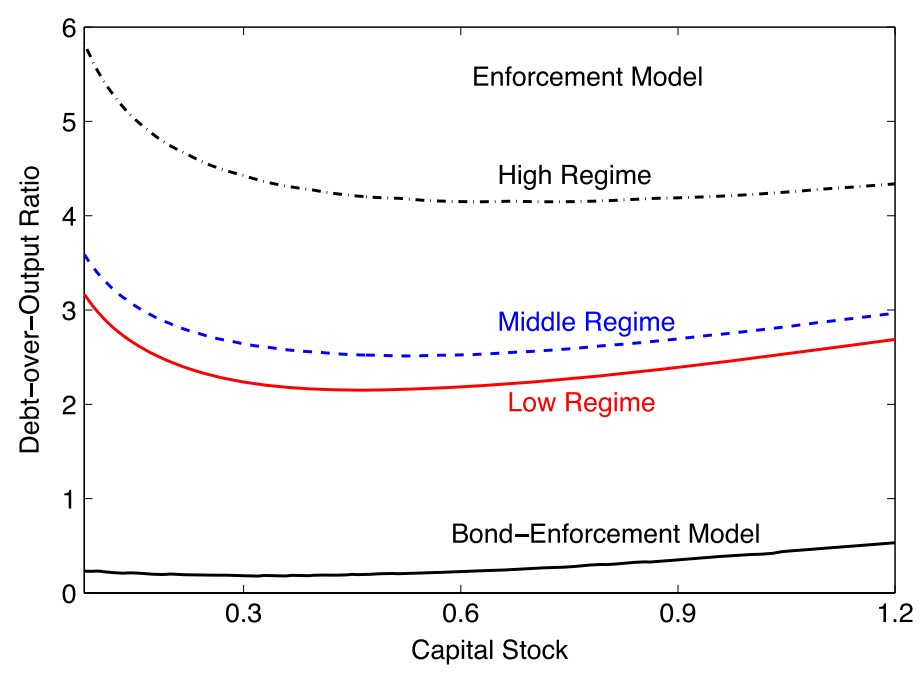

FIGURE 3.-Comparison of endogenous debt limits.

The enforcement model thus generates a capital flow ratio of 0.56 and a ratio of foreign asset and output of 4.1, both of which are much higher than those in the data.

Under these large debt limits, the response of investment to shocks is similar to that found in the frictionless model; the correlation of the investment rate with output growth is 0.83 . Savings starts to respond slightly to the changes of shocks; the correlation between the savings rate and output growth remains low at 0.10 . Consequently, savings and investment rates remain almost uncorrelated, and the relative dispersion of the investment and savings rates is still small, as in the frictionless model. As a result, the enforcement model generates an FH coefficient close to zero.

Default penalties play an important role in determining capital flows under limited enforcement; lenient penalties increase the default incentive and thus reduce borrowing and lending. We conduct a sensitivity analysis on default penalties to examine the robustness of our results. We start with the output drop parameter. As shown in Table V, a smaller output drop reduces capital flows and drives up the FH coefficient, but the effects are quantitatively small. Even under a zero output drop, the enforcement model still produces an FH coefficient close to zero and a large volume of capital flows. In contrast, Kehoe and Perri (2002) found that this default penalty leads to small capital flows. The difference comes from two sources. First, our shock process is more volatile than theirs. We calibrate to TFPs of both developed and developing countries while they calibrate to those of developed countries only. Second, our multicountry model offers more insurance opportunities than their two- 
TABLE V

SENSITIVITY ANALYSIS OF THE ENFORCEMENT MODEL

\begin{tabular}{lccccccc}
\hline \hline & \multicolumn{3}{c}{ Output Loss $\lambda$} & & \multicolumn{3}{c}{ Reentry Probability $\eta$} \\
\cline { 2 - 3 } \cline { 7 - 8 } & $\lambda=2.0 \%$ & $\lambda=0.9 \%$ & $\lambda=0 \%$ & & $\eta=20 \%$ & $\eta=40 \%$ & $\eta=100 \%$ \\
\hline FH coeff (s.e. $)^{\mathrm{a}}$ & $-0.015(0.02)$ & $-0.011(0.02)$ & $-0.009(0.02)$ & & $0.08(0.03)$ & $0.11(0.03)$ & $0.23(0.03)$ \\
$C A / Y$ & 0.57 & 0.55 & 0.51 & & 0.10 & 0.07 & 0.02 \\
$\operatorname{std}(S / Y)$ & 0.29 & 0.27 & 0.26 & & 0.06 & 0.04 & 0.016 \\
$\operatorname{std}(I / Y)$ & 0.04 & 0.04 & 0.04 & & 0.01 & 0.01 & 0.005 \\
$\operatorname{cor}(S / Y, I / Y)$ & -0.10 & -0.08 & -0.06 & & 0.36 & 0.36 & 0.70 \\
\hline
\end{tabular}

${ }^{\text {a }}$ The term s.e. refers to the standard error.

country model. Thus, in our model, there is both a greater need and a greater opportunity to insure, which leads to larger capital flows.

We next relax the assumption of permanent exclusion from international financial markets after default. To give the enforcement model the best chance of matching the data, we shut down the output drop so as to generate the highest possible FH coefficient. The default welfare on the right hand side of the enforcement constraints becomes

$$
\begin{aligned}
V^{D}(a, k)= & \max _{c, k^{\prime}} u(c) \\
& +\beta \sum_{a^{\prime} \mid a} \pi\left(a^{\prime} \mid a\right)\left((1-\eta) V^{D}\left(a^{\prime}, k^{\prime}\right)+\eta W\left(a^{\prime}, k^{\prime}, 0\right)\right),
\end{aligned}
$$

subject to $c+k^{\prime}-(1-\delta) k \leq a k^{\alpha}$, where $\eta$ denotes the reentry probability and $W$ denotes the market welfare of the enforcement model.

Table $\mathrm{V}$ reports the results for different reentry probabilities. As the reentry probability $\eta$ increases, capital flows decrease and the $\mathrm{FH}$ coefficient increases. Even when $\eta$ approaches $100 \%$, the enforcement model still generates an FH coefficient much lower than that found in the data. The capital flow ratio and the dispersions of the savings and investment rates, however, are much lower than those found in the data. To produce the observed FH coefficient, we would need an even lower default penalty: countries can access the markets with some probability in the defaulting period and with certainty in the next period. This seems unrealistic. Gelos, Sahay, and Sandleris (2004) documented that, on average, defaulting countries are excluded from international financial markets for 5 years, which implies an $\eta$ of $20 \%$. Moreover, capital flows and dispersions of savings and investment rates would be even lower.

The enforcement model has a counterfactual implication when the reentry probability is high: countries hit with bad shocks might respond by increasing capital and investment. The reason is as follows. In this model, the demand for capital decreases when shocks are bad or when enforcement constraints 
are binding. With contingent assets, the enforcement constraints tend to bind under good shocks and relax under bad shocks. Bad shocks thus have two effects: they decrease capital due to lower returns, but increase capital due to the relaxation of the enforcement constraints. Hence, capital and investment might increase when countries are hit with bad shocks if the effect of relaxing the binding enforcement constraints is large enough.

This counterfactual implication helps explain why the FH coefficient remains small under high reentry probabilities. As the reentry probability increases, enforcement constraints tighten and capital flows decrease, thereby increasing the savings-investment correlation across countries. This increase in the correlation is dampened by the counterfactual implication as follows. Consider a country that increases investment when hit by a bad shock. Its investment is high, but output and savings are low. Moreover, savings tends to decrease by more than output due to the incentive of consumption smoothing. Thus, this country has a high investment rate and a low savings rate in response to the bad shock. These responses are large enough to lead to a high average investment rate and a low average savings rate. This lowers the standard deviation of the average investment rate and the savings-investment correlation across countries, and dampens the increase in the FH coefficient.

Note that in these experiments we assume that defaulting countries have debt fully written off and are treated the same after reentry as countries that have never defaulted. In the data, the default penalties are more severe because these assumptions are violated. Defaulting countries have only partial debt relief and need to repay a nonnegligible fraction of their outstanding debt when reentering the market. ${ }^{20}$ In addition, though defaulting countries regain access to markets, they may have only limited access and face a higher cost of borrowing relative to nondefaulting countries. If we enrich the enforcement model further along these dimensions, the default penalty will increase, which loosens borrowing limits and lowers the FH coefficient.

\subsection{The Bond Model}

We next examine the bond model, where countries can trade only noncontingent bonds. To isolate the role of limited spanning, we impose natural debt limits, which ensure that countries are able to repay without incurring negative consumption. These debt limits are loose enough such that only a small fraction of countries bind at the constraints in equilibrium. Formally, each country maximizes welfare given by (3) subject to the budget constraints (4) and the natural debt limits (6). As shown in Table IV, the bond model with the natural debt limits produces a small $\mathrm{FH}$ coefficient of 0.05 and a large capital flow ratio of 0.38 .

\footnotetext{
${ }^{20}$ The debt recovery rate is $40 \%$ for Ecuador's 1999 default, 36.5\% for Russia's 1998 default, and $28 \%$ for Argentina's 2001 default.
} 
The investment behavior in the bond model is similar to that in the frictionless model because of the large debt limits. Savings behavior in this model, however, is different due to precautionary motives under incomplete markets; countries tend to save more when the TFP shock increases. Thus, the correlation between the average savings rate and average output growth increases from zero in the frictionless model to 0.41 in the bond model, and similarly for the correlation between the average rates of savings and investment. Despite the increases in the correlation between these two rates, the dispersion of the savings rate is still much larger than that of the investment rate: 0.34 versus 0.04 . This is because the amount of borrowing is virtually unrestricted: the foreign-asset-position-to-GDP ratio is 5.6, which is much higher than 0.49 in the data. As a result, the bond model with the natural debt limits implies a counterfactually small $\mathrm{FH}$ coefficient.

Most of the literature with incomplete markets imposes ad hoc debt limits. When these limits are tightened exogenously, the bond model can generate the observed FH coefficient. This was shown by Castro (2005), who restricted countries to borrow no more than a fraction $\kappa$ of their resources at the beginning of the period:

$$
b\left(a^{t}\right) \geq-\kappa\left(a_{t} k\left(a^{t-1}\right)^{\alpha}+(1-\delta) k\left(a^{t-1}\right)+R_{t} b\left(a^{t-1}\right)\right)
$$

We conduct a similar analysis in the bond model. We find that when $\kappa$ is set at $9.8 \%$, the bond model reproduces the observed FH coefficient. As reported in Table IV, the bond model under the constraint (14) produces similar implications as the bond-enforcement model.

Castro's analysis shows that we need debt limits to be severe enough to restrict capital flows close to the data to resolve the FH puzzle. Although this is an important contribution, Castro's analysis leaves the source of the borrowing constraints unexplained. Our work suggests that the interaction of the two financial frictions could be a potential source for these required borrowing constraints. Moreover, our analysis is useful for predicting the effects on savings, investment, and capital flows if there is a change in default penalties or contracting technologies.

\subsection{Interaction of Two Frictions}

The key reason that the two-friction model can solve the FH puzzle is that the interaction of the two frictions generates tight endogenous debt limits to restrict capital flows close to the data. As shown in Figure 3, the enforcement model under the benchmark default penalties generates loose state-contingent debt limits, which ensure repayments if the contingency occurs. When limited spanning is also introduced, the debt limits become noncontingent to ensure that countries prefer to repay, even under the worst realization of shocks. Clearly, the noncontingent debt limits are tighter than the contingent ones. 
Moreover, market welfare is lower in the two-friction model than in the enforcement model because limited spanning restricts trading opportunities, although the autarky utilities are the same across these two models. Countries thus have larger incentive to default in the two-friction model than in the enforcement model. As a result, the debt limits are further tightened in the presence of both frictions.

In addition, the two-friction model does not have the counterfactual investment behavior in the enforcement model, even when the debt limits are tight. The key is that limited spanning makes repayments noncontingent. Repayments are more painful under bad shocks with lower income, and thus the enforcement constraints tend to bind when countries are hit with bad shocks. Therefore, investment tends to decrease in response to bad shocks as in the data. Absence of the counterfactual implication helps explain why the twofriction model can generate the observed FH coefficient, while the enforcement model cannot under the same capital flow ratio.

The interaction of the two frictions improves the model's quantitative performance along four dimensions over the frictionless model, the enforcement model, and the bond model with the natural debt limits. First, the two-friction model produces a capital flow ratio close to that in the data, while the other three models generate ratios at least 5 times that in the data (see Table IV). Second, the two-friction model generates an observed dispersion of average savings rates of 0.06 , while the other three models generate a dispersion at least 4 times that found in the data. Third, the two-friction model produces a correlation between average savings and investment rates almost the same as that in the data, while this correlation is much lower in the other three models. Last, the two-friction model generates an average savings rate closest to the data, although it underperforms with regard to the average investment rate. The two-friction model has implications in these dimensions similar to the bond model with the exogenous debt limits, which are calibrated to match the observed FH coefficient.

The interaction of the two frictions also helps account for the imperfect risk sharing that is in the data. The empirical literature commonly measures the degree of risk sharing as the coefficient on output growth in a panel regression of consumption growth on output growth. As shown in Table IV, international risk sharing is far from perfect empirically, which is completely at odds with the perfect risk sharing prediction of the complete markets model. The enforcement model and the bond model with the natural debt limits still provide too much risk sharing relative to the data. With the tight debt limits, the bondenforcement model greatly reduces risk sharing across countries and generates a degree of risk sharing that is much closer to that found in the data.

We now examine the impact of default penalties in the two-friction model. When the output loss parameter $\lambda$ is zero, permanent exclusion from financial markets is the only default penalty. Under this scenario, we find that capital flows are small and the FH coefficient is large, as shown in Table VI. In 
TABLE VI

SENSITIVITY ANALYSIS OF THE BOND-ENFORCEMENT MODEL

\begin{tabular}{|c|c|c|c|c|c|c|}
\hline & \multicolumn{3}{|c|}{$\eta=0 \%$} & \multicolumn{3}{|c|}{$\lambda=1.4 \%$} \\
\hline & $\lambda=2.0 \%$ & $\lambda=0.9 \%$ & $\lambda=0 \%$ & $\eta=20 \%$ & $\eta=40 \%$ & $\eta=100 \%$ \\
\hline FH coeff (s.e. $)^{\mathrm{a}}$ & $0.45(0.05)$ & $0.61(0.05)$ & $0.94(0.02)$ & $0.81(0.04)$ & $0.86(0.03)$ & $0.93(0.02)$ \\
\hline$C A / Y$ & 0.11 & 0.09 & 0.01 & 0.04 & 0.03 & 0.02 \\
\hline $\operatorname{std}(S / Y)$ & 0.06 & 0.05 & 0.03 & 0.04 & 0.03 & 0.03 \\
\hline $\operatorname{std}(I / Y)$ & 0.04 & 0.04 & 0.02 & 0.03 & 0.03 & 0.03 \\
\hline $\operatorname{cor}(S / Y, I / Y)$ & 0.72 & 0.84 & 0.99 & 0.94 & 0.96 & 0.98 \\
\hline
\end{tabular}

a The term s.e. refers to the standard error.

contrast, in the enforcement model this default penalty supports large capital flows and generates a close-to-zero FH coefficient. This is because the exclusion from financial markets is less severe when only noncontingent bonds can be traded. Thus, to match the observed capital flows, we need the output loss as part of the default penalties. As the output drop parameter $\lambda$ rises from 0 to $2 \%$, the $\mathrm{FH}$ coefficient decreases from 0.94 to 0.45 , but remains large and positive.

We also experiment with partial exclusion from financial markets in Table VI. We set the output loss at the benchmark value of $1.4 \%$. When the reentry probability is $20 \%$, the model produces a small capital flow ratio of $4 \%$ and a large FH coefficient of 0.81. Capital flows decrease and the FH coefficient rises as we further increase the reentry probability to make default less painful. Again, we assume in all these experiments that the defaulting country has all the debt written off and has full access to the markets upon reentry. If we further relax these assumptions, the FH coefficient will decrease since borrowing limits become looser with higher default penalties.

\subsection{Time-Series and Cross-Section Predictions}

Savings and investment are also positively correlated over business cycles within a country, as documented by Tesar (1991). The international business cycle literature shows that the positive time-series savings-investment correlation arises in either a frictionless model or a model with financial frictions. ${ }^{21}$ We confirm the previous results. Moreover, we highlight that the cross-country dimension, and not the time-series dimension, of savings and investment data helps evaluate the significance of financial frictions. Finally, we demonstrate the success of the two-friction model mechanism in producing key international business cycle statistics.

\footnotetext{
${ }^{21}$ See Backus, Kehoe, and Kydland (1992), Baxter and Crucini (1993), and Mendoza (1991).
} 
To examine the time-series implications, we must introduce capital adjustment costs, as is standard in international business cycle models, so as to reduce the volatility of investment to a level close to that in the data. ${ }^{22}$ Following the literature, we specify the capital adjustment cost as $\chi\left(k_{t+1} / k_{t}-1\right)^{2} k_{t} / 2$, where $\chi$ is calibrated to match the volatility of investment in the data. The resource constraints are modified accordingly to reflect the adjustment costs.

We find that all of the models, with or without financial frictions, generate a positive time-series correlation between savings and investment rates (reported in the last column of Table IV), while the FH coefficients are almost the same as were estimated before. The result comes from endogenous responses of savings and investment to the persistent shock process. When hit by a good shock, a country increases investment to utilize this good production opportunity and also increases savings to smooth consumption. On the other hand, when hit by a bad shock, a country reduces both savings and investment. Thus, savings and investment are positively correlated over time, and this mechanism is present in each of the models.

Different from the time-series dimension, the cross-section dimension studies how divergent the long-term average savings and investment rates are for each country. One can imagine that in a world with a persistent shock process, each country could have positively correlated savings and investment rates over time, but might have very different average savings and investment rates. In this study, we have shown that the degree of divergence depends on the ability of countries to borrow and lend, which in turn is given by the degree of financial frictions. This explains why the cross-section dimension helps evaluate the significance of financial frictions.

We also examine the implications on key international business cycle statistics of the bond-enforcement model. As reported in Table VII, the bond-

TABLE VII

TIME-SERIES IMPLICATIONS OF THE BOND-ENFORCEMENT MODEL ${ }^{\mathrm{a}}$

\begin{tabular}{|c|c|c|c|c|c|c|c|c|c|}
\hline & \multicolumn{4}{|c|}{ Volatility } & \multicolumn{3}{|c|}{ Cyclicality } & \multicolumn{2}{|c|}{ International } \\
\hline & $\operatorname{std}(y)$ & $\operatorname{std}\left(\frac{n x}{y}\right)$ & $\frac{\operatorname{std}(c)}{\operatorname{std}(y)}$ & $\frac{\operatorname{std}(i)}{\operatorname{std}(y)}$ & $\operatorname{cor}(c, y)$ & $\operatorname{cor}(i, y)$ & $\operatorname{cor}\left(\frac{n x}{y}, y\right)$ & $\operatorname{cor}\left(y, y^{*}\right)$ & $\operatorname{cor}\left(c, c^{*}\right)$ \\
\hline Data & $3.53 \%$ & $5.59 \%$ & 1.01 & 4.08 & 0.74 & 0.58 & -0.15 & 0.08 & 0.05 \\
\hline Model & $3.35 \%$ & $3.18 \%$ & 0.68 & 4.04 & 0.98 & 0.78 & 0.09 & 0.02 & 0.02 \\
\hline
\end{tabular}

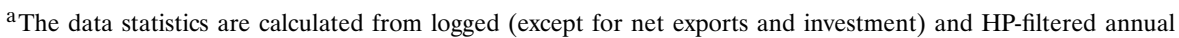
time series, 1960-2003. The model statistics are averages from 1,000 simulations of 64 series and 44 periods, where the relevant series have been logged and HP-filtered as in the data series. All statistics are averages across countries. std denotes the standard deviation, cor denotes the correlation, $y$ denotes output, $c$ denotes consumption, $i$ denotes investment, and $\mathrm{nx}$ denotes net exports. The relative standard deviation of investment and output is computed using the growth rates, since investment might be negative in the model.
}

\footnotetext{
${ }^{22}$ We did not impose the capital adjustment cost in the enforcement model, due to technical complexity.
} 
enforcement model generates fluctuations of output, consumption, and net exports close to those observed in the data. It also comes close to matching the cyclical behavior of consumption and investment. In addition, the model generates a cross-country output correlation that is the same as the consumption correlation due to limited risk sharing under the tight endogenous debt limits. These tight constraints, however, also limit the model's ability to generate the countercyclicality of net exports found in the data. ${ }^{23}$

\section{CONCLUSION}

The Feldstein-Horioka finding of a positive long-run savings-investment correlation across countries is one of the most robust findings in international finance. Our work first shows that this finding is a puzzle for the frictionless (complete markets) model. To our knowledge, this point is new to the literature. Most existing theoretical studies examine the positive time-series savingsinvestment correlation in the data and find this observation can arise even in a frictionless model as savings and investment comove in response to productivity shocks. We find, however, that the frictionless model implies a correlation of zero between the long-run savings and investment rates across countries.

Our work then quantitatively investigates whether plausibly calibrated financial frictions can explain this finding. We find that a calibrated model with both limited spanning and limited enforcement frictions produces a savingsinvestment correlation and capital flows close to those found in the data. In contrast, the model with limited enforcement alone cannot jointly produce the capital flows and the FH coefficient found in the data. The model with limited spanning produces this finding when we exogenously set debt limits to restrict the volume of capital flows consistent with the data. The two frictions together generate such debt limits endogenously through their interaction. In sum, our work analyzes the roles of different financial frictions in one harmonized framework and highlights the importance of the interaction between the two frictions.

In this work, the limited enforcement friction endogenizes borrowing constraints and links them to the fundamental parameters of the default penalties. This analysis is useful for predicting international capital flows when the underlying default penalties change. On the other hand, the two-friction model still assumes that the contracts available are exogenously incomplete and does not provide a deep reason for debt to be noncontingent. A future extension is to endogenize the set of contracts available.

Another interesting extension would be to allow for equilibrium default, since in the data we do observe frequent episodes of sovereign default. In our bond-enforcement model, default never occurs in equilibrium because the endogenous borrowing constraints ensure that countries repay their debt under

${ }^{23} \mathrm{~A}$ similar result is also found in Kehoe and Perri (2002). 
any future contingency. If endogenous debt contracts are instead set to ensure debt repayments only in expectation, default might occur in equilibrium. ${ }^{24}$ Theoretically, equilibrium default could improve welfare by providing state contingency in debt repayments upon default. It is still an open question whether such an extension could have a significant effect on the savings-investment correlation.

\section{APPENDIX A: DATA SAMPLE AND SOURCES}

In this appendix, we describe our data source, identify the countries in our sample, and document several important changes in the systems of national accounts.

\section{A.1. Data Sources}

Our nominal data series are from the World Bank's publication World Development Indicators 2007. These include nominal GDP, nominal final consumption, and nominal gross capital formation. Our population and real data series are from the Penn World Table 6.2 (Heston, Summers, and Aten (2006)). These series include real GDP per capita (Laspeyres), shares of consumption, government expenditure, and investment. Total employment data are mainly from data bases compiled by the Groningen Growth and Development Centre. The missing employment data are supplemented by the Penn World Table 6.2 as

$$
\text { employment }=\frac{\text { real GDP per capita }(\text { chained }) \times \text { population }}{\text { real GDP per worker }(\text { chained })} .
$$

The data on capital flows are from the data set compiled by Lane and MilesiFerretti (2007).

\section{A.2. Country Sample}

A total of 98 countries have all relevant data series available for our whole sample period (1960-2003). We select the ending year to be 2003 because the Penn World Table 6.2 has missing data for many countries in 2004. We exclude economies that have a real GDP per capita of less than $4.5 \%$ or a population of less than $1 \%$ of those in the United States in 2000. We also exclude Luxembourg, Hong Kong, Taiwan, and China. The 64 countries remaining in the sample are Algeria, Argentina, Australia, Austria, Belgium, Bolivia, Brazil, Cameroon, Canada, Chile, Colombia, Costa Rica, Côte d'Ivoire, Denmark, the Dominican Republic, Ecuador, Egypt, El Salvador, Finland, France, Germany, Greece, Guatemala, Guinea, Honduras, Iceland, India, Indonesia, Iran,

\footnotetext{
${ }^{24}$ See Eaton and Gersovitz (1981), Arellano (2007), Chatterjee, Corbae, Nakajima, and RiosRull (2007), and Livshits, MacGee, and Tertilt (2007).
} 
Ireland, Israel, Italy, Japan, Korea, Malaysia, Mexico, Morocco, the Netherlands, New Zealand, Nicaragua, Norway, Pakistan, Panama, Paraguay, Peru, the Philippines, Portugal, Romania, Senegal, Singapore, South Africa, Spain, Sri Lanka, Sweden, Switzerland, the Syrian Arab Republic, Thailand, Tunisia, Turkey, the United Kingdom, the United States, Uruguay, Venezuela, and Zimbabwe.

\section{A.3. Changes in Systems of National Accounts}

Our result for the 16 OECD countries Feldstein and Horioka (1980) used over 1960-1974 is 0.67, which is different from the estimate of 0.89 found in the original study because of changes in the systems of national accounts (SNA). In the data source they used, National Accounts of OECD Countries 1974, the 1953 SNA, and the 1968 SNA are used for these countries. In our data source, the World Development Indicators 2007, most countries use the 1993 SNA. The adoption of the 1993 SNA involves many changes. Some changes are simply reclassifications of items between various components of GDP, but others involve adding new transactions or suppressing old ones. Among all of the components of GDP, the largest overall revisions affect gross fixed capital formation. The 1993 SNA broadens the concept of investment to include several types of expenditure that were not formerly considered to be capital spending, such as spending on computer software and expenditures on mineral exploration, entertainment, and artistic works. The above changes lead to an upward revision of gross capital formation and to a decrease in the FH coefficient.

\section{APPENDIX B: ESTIMATION OF THE WORLD PRODUCTIVITY PROCESS}

The TFP level for country $i$ at period $t$ is defined as

$$
\log A_{t}^{i}=\log Y_{t}^{i}-\alpha \log K_{t}^{i}-(1-\alpha) \log L_{t}^{i},
$$

where $Y_{t}^{i}$ is real GDP, $K_{t}^{i}$ is the capital stock constructed from gross capital formation data, and $L_{t}^{i}$ is employment. The average growth rate of the TFP series of 64 countries $g_{a}$ is $1.01 \%$.

In this appendix, we describe the expectation maximization (EM) algorithm used to obtain the maximum likelihood estimates of parameters in the regimeswitching process specified in (11). This is an extension of the EM principle of Hamilton (1989). The log-likelihood function is given by

$$
L(\Psi ; \Theta)=\sum_{i=1}^{N} \log \left(f\left(\Psi^{i} ; \Theta\right)\right),
$$

where $\Psi^{i}=\left\{a_{i T}, a_{i T-1}, \ldots, a_{i 1}\right\}$ is a vector containing all the observations on country $i$ 's TFP, $\Theta=\left\{\left\{\mu_{j}, \rho_{j}, \nu_{j}\right\}_{j=1,2,3}, P\right\}$ denotes the parameters to be estimated, $N$ denotes the number of countries, and $T$ denotes number of periods. 
The density function $f$ is given by

$$
\begin{aligned}
f\left(\Psi^{i} ; \Theta\right)= & \sum_{m^{i}} f\left(a_{i T} \mid m_{i T}, a_{i T-1} ; \Theta\right) \cdots f\left(a_{i 2} \mid m_{i 2}, a_{i 1} ; \Theta\right) \\
& \times p\left(m_{i T} \mid m_{i T-1}\right) \cdots p\left(m_{i 2} \mid m_{i 1}\right) p\left(m_{i 1}\right),
\end{aligned}
$$

where $m_{i t}$ denotes the regime that country $i$ is in at period t.

To make computation feasible, we assume the process to be stationary and restrict $\rho \leq 0.995$ in the estimation. Due to the nonlinearity of the maximum likelihood function, we cannot solve the parameters analytically. Instead, we use the EM algorithm to solve the maximum likelihood estimates iteratively. We start with an initial guess of the parameters $\Theta_{n-1}$. We then update the conditional probability of each regime in each period for each country using the Bayes rule. Next, given the conditional probabilities, we compute $\Theta_{n}$ with the maximum log-likelihood method. We iterate these procedures until $\Theta_{n}$ converges.

\section{REFERENCES}

Abraham, A., AND E. CARCElEs-PovedA (2010): "Endogenous Trading Constraints With Incomplete Asset Markets," Journal of Economic Theory (forthcoming). [606]

ABReU, D., D. PEARCE, AND E. STACCHETTI (1990): "Toward a Theory of Discounted Repeated Games With Imperfect Monitoring," Econometrica, 58 (5), 1041-1063. [612]

AIYAGARI, S. R. (1994): “Uninsured Idiosyncratic Risk and Aggregate Saving," Quarterly Journal of Economics, 109 (3), 659-684. [604,611]

AREllano, C. (2007): "Default Risk, the Real Exchange Rate and Income Fluctuations in Emerging Economies," American Economic Review, 98 (3), 690-712. [628]

ATKESON, A. (1991): "International Lending With Moral Hazard and Risk of Repudiation," Econometrica, 59 (4), 1969-1989. [612]

ATKeson, A., AND R. E. LuCAS JR. (1992): "On Efficient Distribution With Private Information on Efficient Distribution With Private Information," Review of Economic Studies, 59 (3), 427-453. [619]

BaCKUS, D. K., P. J. KehOE, AND F. E. Kydland (1992): "International Real Business Cycles," Journal of Political Economy, 100 (4), 745-775. [625]

BAI, Y., AND J. ZHANG (2010): "Supplement to 'Solving the Feldstein-Horioka Puzzle With Financial Frictions'," Econometrica Supplemental Material, 78, http://www.econometricsociety. org/ecta/Supmat/6619_extensions.pdf; http://www.econometricsociety.org/ecta/Supmat/6619_ data and programs.zip. $[606,611,612]$

BARRo, R. J., N. G. MANKIW, AND X. SALA-I-MARTIN (1995): "Capital Mobility in Neoclassical Models of Growth," American Economic Review, 85 (1), 103-115. [606]

BAXTER, M., AND M. J. CRUCINI (1993): "Explaining Saving-Investment Correlations," American Economic Review, 83 (3), 416-436. [605,625]

(1995): "Business Cycles and the Asset Structure of Foreign Trade," International Economic Review, 36 (4), 821-854. [604]

Bulow, J., AND K. Rogoff (1989): "Sovereign Debt: Is to Forgive or Forget?" American Economic Review, 79 (1), 43-50. [609]

CASTRO, R. (2005): "Economic Development and Growth in the World Economy," Review of Economic Dynamics, 8 (1), 195-230. [605,623] 
Chatterjee, S., D. Corbae, M. NAKajima, And J.-V. Rios-Rull (2007): “A Quantitative Theory of Unsecured Consumer Credit With Risk of Default," Econometrica, 75 (6), 1525-1589. [628]

ClARIDA, R. H. (1990): "International Lending and Borrowing in a Stochastic Stationary Equilibrium," International Economic Review, 31 (3), 543-558. [609]

COAKLEY, J., F. KULASI, AND R. SMITH (1998): “The Feldstein-Horioka Puzzle and Capital Mobility: A Review," International Journal of Finance and Economics, 3 (2), 169-188. [607]

COHEN, D. (1992): “The Debt Crisis: A Postmortem," NBER Macroeconomics Annual, 7, 65-105. [610]

EATON, J., AND M. Gersovitz (1981): "Debt With Potential Repudiation: Theoretical and Empirical Analysis," Review of Economic Studies, 48 (2), 289-309. [609,628]

FELDSTEIN, M., AND C. HORIOKA (1980): "Domestic Saving and International Capital Flows," Economic Journal, 90 (358), 314-329. [603,606,629]

Frankel, J. A. (1992): “Measuring International Capital Mobility: A Review," American Economic Review, 82 (2), 197-202. [607]

Gelos, R. G., R. SAHAY, AND G. SANDLERIS (2004): "Sovereign Borrowing by Developing Countries: What Determines Market Access?” Working Paper 04/221, IMF. [621]

Hamilton, J. D. (1989): "A New Approach to the Economic Analysis of Nonstationary Time Series and the Business Cycle," Econometrica, 57 (2), 357-384. [614,629]

Heston, A. R., R. Summers, And B. Aten (2006): "Penn World Table Version 6.2," Center for International Comparisons at the University of Pennsylvania. [628]

JESKE, K. (2006): "Private International Debt With Risk of Repudiation," Journal of Political Economy, 114 (3), 576-593. [611]

KeHOE, P. J., AND F. PERRI (2002): "International Business Cycles With Endogenous Incomplete Markets,” Econometrica, 70 (3), 907-928. [604,605,611,620,627]

KeHOE, T. J., AND D. K. LeVINE (1993): "Debt-Constrained Asset Markets," Review of Economic Studies, 60 (4), 865-888. [604]

Kocherlakota, N. (1996): "Implications of Efficient Risk Sharing Without Commitment," Review of Economic Studies, 63 (4), 595-609. [604]

LANE, P. R., AND G. M. Milesi-Ferretti (2007): "The External Wealth of Nations Mark II," Journal of International Economics, 73 (2), 223-250. [628]

Livshits, I., J. MACGEE, AND M. TerTilt (2007): “Consumer Bankruptcy: A Fresh Start,” American Economic Review, 97 (1), 402-418. [628]

LuCAS, R. E. (1990): “Why Doesn't Capital Flow From Rich to Poor Countries?" American Economic Review, Papers and Proceedings of the Hundred and Second Annual Meeting of the American Economic Association, 80 (2), 92-96. [619]

MendozA, E. G. (1991): "Real Business Cycles in a Small Open Economy," American Economic Review, 81 (4), 797-818. [604,605,625]

OBSTFELD, M. (1986): "Capital Mobility in the World Economy: Theory and Measurement," Carnegie-Rochester Conference Series on Public Policy, 24, 55-103. [606]

Summers, L. H. (1988): “Tax Policy and International Competitiveness," in International Aspects of Fiscal Policies, ed. by J. Frenkel. Chicago: Chicago University Press, 349-375. [606]

TESAR, L. L. (1991): "Savings, Investment, and International Capital Flows," Journal of International Economics, 31 (1-2), 55-78. [605,625]

Tomz, M., AND M. L. Wright (2007): “Do Countries Default in 'Bad Times'?” Journal of the European Economic Association, 5 (2-3), 352-360. [610,613]

WestPHAL, U. (1983): “Domestic Saving and International Capital Movements in the Long Run and the Short Run' by M. Feldstein," European Economic Review, 21 (1-2), 157-159. [606]

Wright, M. L. (2006): "Private Capital Flows, Capital Controls and Default Risk," Journal of International Economics, 69 (1), 120-149. [611]

ZHANG, H. H. (1997): "Endogenous Borrowing Constraints With Incomplete Markets,” Journal of Finance, 52 (5), 2187-2209. [604,605] 
ZHANG, J. (2005): “Essays on International Economics,” Ph.D. Dissertation, University of Minnesota. [619]

Economics Dept., Arizona State University, Tempe, AZ 85287, U.S.A.; yan. bai@asu.edu

$$
\text { and }
$$

Dept. of Economics, University of Michigan, 611 Tappan St., Ann Arbor, MI 48109, U.S.A.; jzhang@umich.edu.

Manuscript received August, 2006; final revision received September, 2009. 